\title{
Post-industrial urban strategies
}

\author{
B. Niemann ${ }^{1,2} \&$ P. Schädler ${ }^{1}$ \\ ${ }^{1}$ NIEMANN+STEEGE, Düsseldorf, Germany \\ ${ }^{2}$ University Leipzig, Germany
}

\begin{abstract}
In times of the continuous transformation of urban structures in terms of growth and shrinkage, sprawl and the compact city, adaption and individuality, the only possibility for planners to cope with these circumstances while considering steadily changing parameters, is a strategic design approach. This means developing concepts based on variety, flexibility and stability at the same time: On the one hand, the intactness - or wholeness - referring to the existent context, on the other, the openness for future trends.

Life cycles of cities and buildings are decreasing. Especially infrastructural systems which were generously created in the post-war period significantly shaping our landscapes are now shifted, transformed or revitalized. These spaces, together with the numerous industrial wastelands that are occurring, open up opportunities to become motors of city developments.

It might be that the deficits in frequently criticized modern urban design practices are less related to the quality of individual buildings but rather in the neglect of gaps and the spaces in between them. As cities cannot be planned as a whole, but with subspaces being optimized partially independent from each other, the lack of coherence tends to create landscapes made of isolated fragments with an insular character, dominated by commercial districts, shopping malls, airports or museums.

Strategic approaches for the post-industrial city pursue the re-appropriation of abandoned sites. With the means of innovative and unusual utilization concepts (temporary uses, promotion of public spaces, urban agriculture and others), formerly separated quarters can become part of a coherent spatial network - and therefore create a vibrant urban fabric appealing to its citizens.
\end{abstract}

Keywords: post-industrial, strategic design, open wholeness, flexibility. 


\section{The perforated city}

Sustainability, suburbanization, Metrozones, Zwischenstadt, renewal, mosaic, sprawl, compact city - keywords as these characterize the $21^{\text {st }}$ century planning discourses. The current situation in Europe is not merely related to compactness, it can still rather be described as perforated because growing and shrinking processes cause the shift of cities into landscapes and vice versa. Spatial coherences are weakened, connections partially separated. Those polarities along with steadily changing parameters trigger rethinking the future of the city and especially the role of metropolitan landscapes which attain more importance in the context of valorizing urban-rural boundaries. From a designing point of view, it is an essential question, how the perforation of contemporary landscape urbanism can be treated. Which are the challenges? Which tools are already existent, which have to be invented?

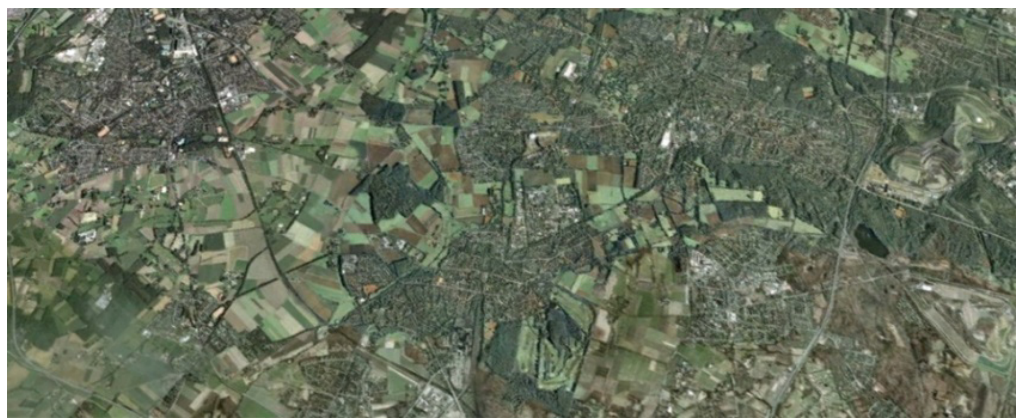

Figure 1: $\quad$ Urban landscape Ruhr Area / Germany.

\section{Generic space}

Fundamental ideas on the comprehension of urban landscapes were discussed by the sociologist Henri Lefèbvre in the 1970s: "Urbanization (urbanized space, urban landscapes) is not visible. We cannot see it yet. Is that only related to the fact that our landscape is influenced by the former landscape and not able to recognize this new space?" [1]. This was intensified with the debates on Thomas Sieverts' "Zwischenstadt" and the Ladenburger Kolleg on the "qualification of the urbanized landscape". These days we are talking of Metrozones in this context. The scientific discussions are characterized by the dispute whether urban landscapes are generic or generally common but also specifically describable landscapes.

According to Rem Koolhaas "The Generic City" [2] describes the co-existent diversity and boredom within the worldwide metropoles: "The generic city is what remains when major parts of urban life are transferred to Cyberspace. [...] It is no more than the reflection of contemporary requirements and abilities. It is a city without history." It seems that Koolhaas is somewhere between rejection and admiration of the generic city. It appears to be the attack on identity, in spite 
of the existence of skyscrapers it does not necessarily seem to be dense and therefore it does not generate an urban culture.

Yet, the perforated generic city obviously offers chances for future developments because non-harmonic situations will generate enough tension to trigger new urban projects. In this sense perforation can function as an incubator of productive urban transformation processes. If it is possible to design new structural orders of space, perforation can accelerate the crisis of the unity of a city and sustainably influence the quality of space.

It is an essential question how in terms of practice and design the perforation of the contemporary city can be coped. What exactly secures the strength and robustness of an urban plan against unforeseeable - positive and negative developments? Which economical, political and social conditions are required then?

\section{Strategy and process optimization}

Life cycles of buildings and cities are decreasing: Infrastructural systems are created and shifted after ten years; industrial areas are transformed to residential complexes after 50 years and vice versa. The insecurity of growth, speed, durability and realization process requires a strategic design approach which conceptually covers the possibility to react on unforeseeable influences. It is the only way to find sustainable structures relatively open for different uses that do not correspond to trivial real-estate thinking.

The usual method of determining spatial and temporal aspects of urban developments in the form of masterplans does not offer sufficient resilience against changing conditions. This is the main problem of designing towards an exactly defined end condition: The loss of individual system components threatens the functionality and existence of other parts or, in the worst case, the entire structure.

In order to avoid this risk, strategic or process-oriented design considers both spatial as well as temporal aspects of the design phase. Possible modifications of external conditions are involved, always closely related to legal, financial and political requirements but also goals and contents of the project.

Strategic planning enables the implementation of development goals during a long period without actually knowing future trends. In the sense of risk management, besides the evaluation of potentials of a project there also need to be estimations on obstacles that might threaten them. This can be done through the simulation of future scenarios (best case / worst case) that take into consideration a large diversity of possible developments.

\section{Three principles of strategic design}

\subsection{Spatial frameworks}

Cities are not created in one piece but they are the result of numerous individual decisions. Urban space does have a crucial significance: it functions as a 
framework and divides the city into different plots. For these neutral spaces of the grid without any coherence, the spatial framework becomes the shaping element.

When questioning "How is it possible to think of the city without imagining the space it occupies and acquires?" Henri Lefèbvre [1] has already explained the meaning of space for the city in 1974. Umberto Eco calls architecture "the art, to articulate space" [3]. This crucial competence, articulating space, has regained up-to-dateness in urbanism discourses. The ability to remember the built environment is related to its quality. Through the movement within space it is perceived by the beholder, kept in mind and saved as an image. In the negative and in the positive sense we are immediately influenced by this experience.

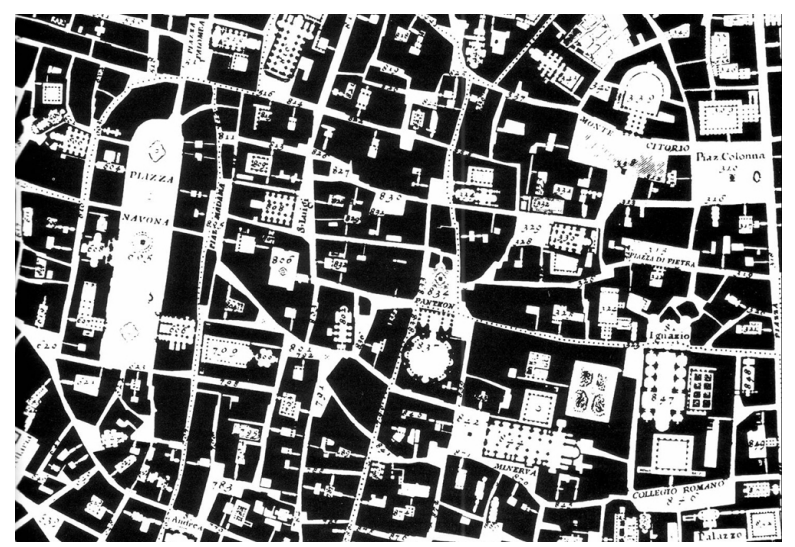

Figure 2: $\quad$ Nolli Plan of Rome.

The Nolli Plan of Rome (1748) addresses the mergence of urban and architectural space. The city is displayed as a figure ground plan with a number of buildings as cavity volumes. The interior of the Pantheon - and some other sacred buildings - are comprehended as being part of urban open space. Already back then, the city was read and staged as a structure of spatial sequences, a dialog between city and architecture. The building's exterior space is the interior space of the city fabric: while in the historical city this seems to be a self-evident fact, nowadays it often falls into oblivion.

It could be concluded that the deficits of the highly criticized modern urban planning - the inhospitality of our cities - is less related to the quality of individual buildings, because these usually function formally as solitaires, but moreover in the neglect of the spaces in-between them and their relation towards each other. With a lack of interaction, a landscape made of isolated fragments with an insular-like character might occur, dominated by commercial parks, shopping centers, airports of museum islands. Counteracting this phenomenon, the coherence of pieces must become a central concern.

Openly accessible public spaces (squares, corridors, greenery etc.) can be important connectors within the spatial frameworks. Cities that leave a positive 
impression behind are mostly those with distinctive public areas because those spaces are the only locations allowing for an exchange between our world of living and working and the urban fabric. Privatization of public spaces, overutilization and commercialization as well as desertification, standardization and trivialization need to be avoided.

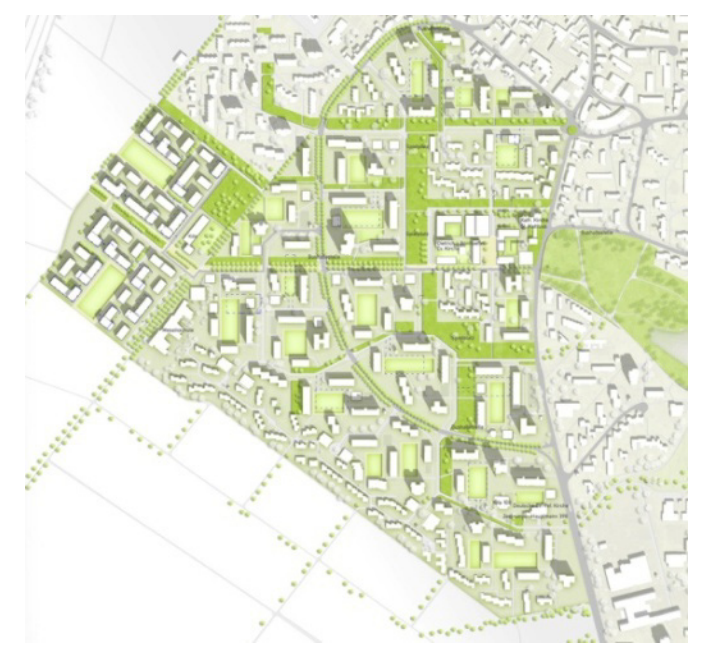

Figure 3: Frankfurt / Main, Northwestern City $(\mathrm{N}+\mathrm{S}$ with RMP LA, rheinflügel severin).

For the success of urban transformation processes, clearly defined open spaces with buildings oriented towards them can play a key role. Those form a static connecting system and a spatial framework for the newly built structures along their edges. Thereby a robust urban structure is generated where flexibility and variety are possible without the loss of context.

The example of the transformed Northwestern City of Frankfurt demonstrates that spatial frameworks cannot only be successfully implemented on vacant wastelands but also within already existent urban structures.

In Delirious New York (1978), Rem Koolhaas [4] observes that the decision for the famous grid of Manhattan, originated in 1814, was mainly based on a speculative act rather than pragmatic reflections. Anyhow, the extension of New York City on the island of Manhattan has received its still characterizing structure with the Commissioner's Plan. The main element - the rectangular street arrangement also known as the grid - is a neutral framework: all plots were equal and did not designate a center. They resembled containers which were open for any kind of use; additionally this system enabled an easy orientation. It seems that the speculative grid combines a maximum of planning efficiency, the standardized division of the entire space, with the largest possible openness of what actually happens. 


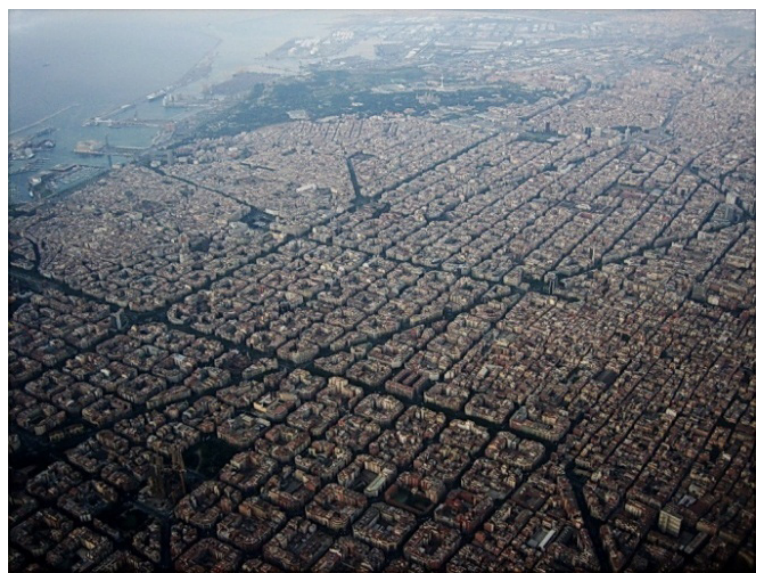

Figure 4: $\quad$ Ensanche District Barcelona.

The Ensanche District in Barcelona [5] is based on a stable spatial framework with the ability to transform the urban fabric without the neglect of the existent context. The area designed by Ildefons Cerdà in 1855 was addressing the basic needs of the city's inhabitants: primarily sunlight, ventilation, vegetation. The street grid was optimized for pedestrians and the transportation of people. The originally planned four-storey open rows have been densified and transformed to nine-storey perimeter blocks. Furthermore the Plan General Metropolitano of the 1980s addresses the re-appropriation of inner courtyards as green spaces for public and semi-public uses by the inhabitants. Ensanche can be considered to be an example of the steadily renewing contemporary city.

The spatial frameworks of these realized conceptions in New York City and Barcelona are distinctive to such an extent that strategic zonings and constructive rules allow to develop a structure that enables a gradual transformation of the existent urban fabric still capable of fulfilling the demands of changing parameters. One can assume that the quality and potentials are not based on their typological coherence or their unity in terms of materials and height but moreover in the resulting capacity to involve "foreign objects" such as public buildings or high-rises without jeopardizing the spatial framework. But where there are no such stable frameworks, integrative concepts that trigger the interweavement of adjacent quarters are necessary. Architectural urbanism designs the framework that can then be used, inhabited, assimilated, and thus be changed accordingly.

\subsection{Creating addresses}

New York City's Central Park is an example of a clearly defined public space within the city center that is popular and highly frequented. The addresses around it are among the most expensive in the city. The park itself significantly shapes the spatial grid of New York and accommodates a variety of activities. It 
forms a border for several neighborhoods and thereby functions as an urban connector between many different social groups from high-income to low and middle income. Furthermore a number of museums are located along its edge contributing to a vibrant urban structure.

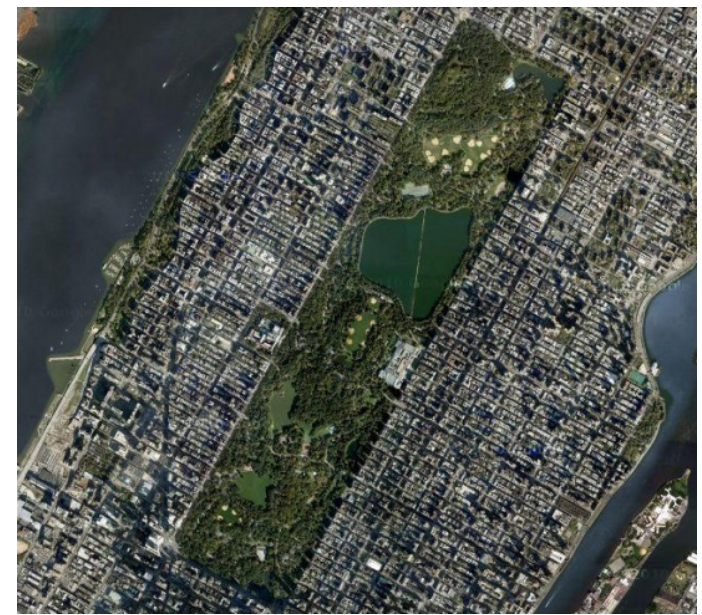

Figure 5: $\quad$ Central Park New York.

Since 1989 the entire urban area of Lyon has been transformed with more than 150 public squares using a limited number of materials, plants and fixtures. Famous urban designers and landscape artists were involved to remodel the metropolitan area. Due to a common set of guidelines, each square is part of a coherent space but it still has its uniqueness. These interventions are part of an overall planning policy which also includes a new lighting plan, a green plan (protection of nature), a blue plan (development of river banks) and a color plan (colors imposed along the quays and large complexes).

Both of the projects are successful with the public but interestingly they have followed quite opposite concepts. Whereas Central Park could be considered to represent a traditional and older model for open spaces, being an inflexible body within the city, the Lyon projects follow the idea of "open wholeness" in the sense that the series of distinct colonies still following certain rules and guidelines expresses a strategy triggering a large variety of possible urban solutions. The overall planning policy is clear, yet it is open enough to allow for uniqueness and individuality on each particular plot.

A sufficient proportion of open space is of major importance in order to reach a greater biodiversity and heterogeneity within the city. Even in the age of communication, Internet and virtual meetings, the urban future will not get along without these public squares, parks or streets. Their importance is related to the task of creating human life quality and fostering the exchange of the city's inhabitants.

Creating central open spaces and urban addresses appears to be a successful conceptional strategy. It is generally reasonable to orient buildings towards 
attractive public open spaces because along this edge between green urban spaces and the buildings the most prominent addresses are present. Especially elongated green axes might be dynamic activation motors for their surroundings. Through the clearly contoured public space, different urban fragments interact with each other. Streets, squares and parks can be buffer zones and communication areas between quarters with a distinctively different character, density and mixture. The intersection points can trigger the development of innovative urban spaces, built forms, programs and therefore new ways of urban life.

\subsection{Designation of plots}

In terms of dynamical, regulative urban planning in temporally and spatially independent yet complementing implementations, every single component of the realization is supposed to contain common urban qualities such as a genetic code. This code is formulated in the form of abstract rules, patterns and recommendations which allow for a high variability of the design without neglecting the dependence from an urban context.

This information being a sort of program includes typological, structural and design aspects as well as elements of open space planning, access systems and guidelines for the utilization and utilization rights. According to this, urban units can - taking external requirements into consideration - develop independently from each other.

With the designation and definition of zonings for the development area, for instance in the Mercator Quarter project in Duisburg, open urban images are generated. Guidelines for the buildings define which parameters are obligatory

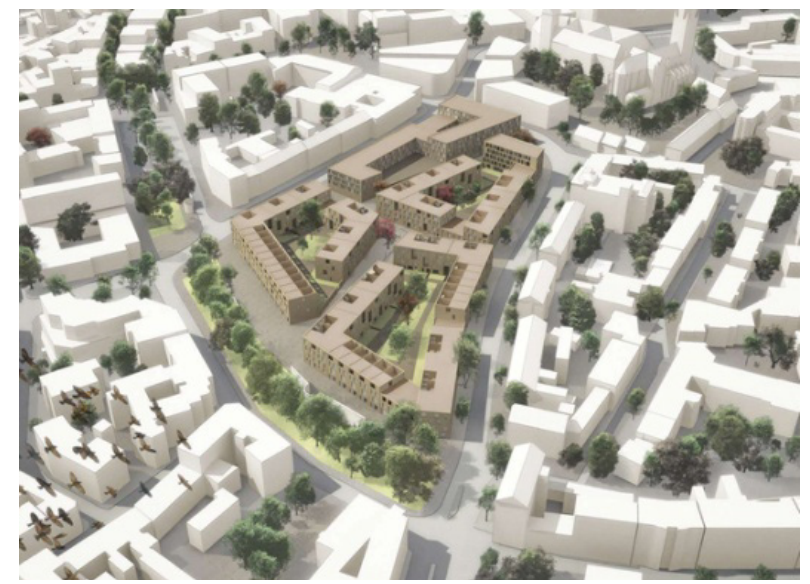

Figure 6: Duisburg Mercator Quarter $(\mathrm{N}+\mathrm{S}$ with Eller+Eller, jbbug LA, rheinflügel severin). 
and which can be freely interpreted. Densities between the particular plots are described; publicly oriented ground floor zones and areas with open and closed spatial edges are defined.

\section{Opportunities of urban agriculture}

Small scale interventions and temporary uses are more and more enriching the list of possible ways to designate plots. Fostering social exchange and public activities, unconventional forms of urban agriculture find an increasing number of supporters worldwide. Community Gardens, Jardins Partagés, City Farms farming seems to be no longer limited to rural areas anymore but reaches periurban areas and even city centers. Especially in Europe where the post-industrial age has let an increasing number of urban fallow sites occur, the so-called "waiting lands" which have lost their former functions offer opportunities to realize innovative spatial concepts. Through the strategic design approach they can enable the re-appropriation of space and trigger the reconnection of formerly separated quarters.

The Prinzessinnengarten in Berlin was a 6000 square meter fallow site that has been occupied and rented by the organization "Nomadisch Grün" aiming at transforming this area into a plot for ecological and social urban agriculture. The garden that emerged this way does not only produce local groceries, it also creates a new location of urban life and meeting space for neighbors and interested citizens. Absolute mobility is a basic principle of the organization, being capable of relocating the entire structure easily.

Also in many other cities in the world, especially in southern regions, urban agriculture is gaining importance. In the 1990s the "agricultura urbana" has become famous in Cuba, bringing market gardening back to the city. The most famous and successful urban gardens are probably the community gardens existing since the 1970s in northern American cities such as New York. Although there are certain difficulties to cope with ranging from infertile soils, fine-dust pollution, shading and aridity, a lot of positive and more dominant aspects are connected with this form of gardening: the activation of socially weak quarters, supply with groceries, fostering biodiversity, reduction of $\mathrm{CO}_{2}$, improvement of the microclimate through local cooling, prevention from "unhealthy" building densities, beautification of wastelands and the reviving of the city in general.

From a planning point of view and in the long-term perspective the quality of life in disadvantaged quarters can be raised through urban gardening activities to such an extent that entire quarters become more attractive and even more expensive - which means that even processes of gentrification might happen. The revitalization of quarters appears to be especially interesting considering shrinking cities such as Dessau/Germany or Detroit.

Urban agriculture promotes social and spatial diversity in the city, fostering the development of a vibrant high quality environment appealing to its citizens. So called "spaces of subsistence" are an important component crossing the 


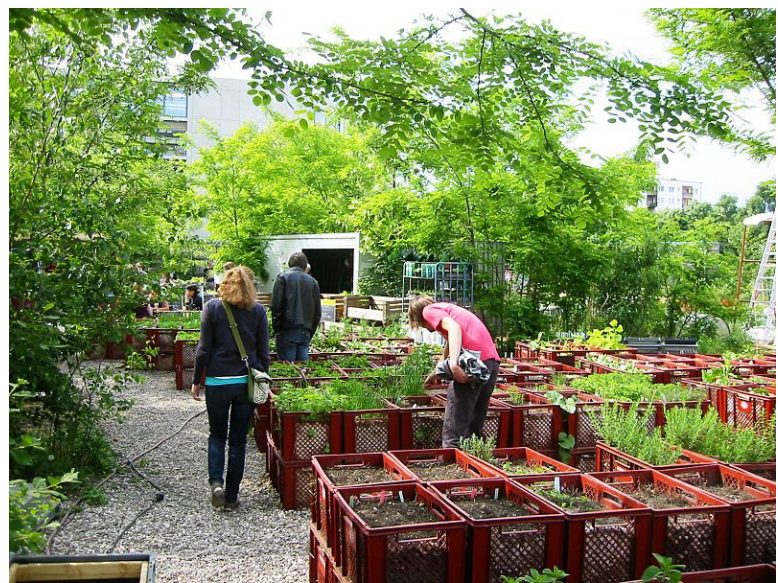

Figure 7: $\quad$ Prinzessinnengarten Berlin.

border from a fossil, non-sustainable economy to a post-fossil one. The possible self-supply with groceries is connected with a sustainable and healthy way of life and decreases the carbon-footprint of the city. As an example: Even the 8 million metropolis London, way more densely populated than all German cities, can cover $30 \%$ of the local demand of fruit and vegetables.

Besides the fact that urban agriculture can be considered as a social strategy, triggering interaction, communications and exchange, it also makes sense from economical as well as ecological points of view. For sure, it will not bring a profitable harvest to be sold on a large scale but it is a low-cost cultivation of empty spaces and it does have the potential to prevent them from becoming dumping sites.

\section{Leipzig Bayerischer Bahnhof}

The Bavarian Station in Leipzig marks the southern edge of the city center and is among the most significant still existent station buildings in Germany. The plot a de-urban space that used to separate western and eastern quarters - is replaced by an agricultural scenic park. Thereby pathways and visual connections from the surroundings are continued and connected with the city center axis. Transformed fallow railway spaces are supposed to be used as neighborhood gardens that have socially and spatially linking functions shaping and characterizing the environment by creating an appealing atmosphere.

The former rupture within the urban fabric becomes a point of interface which is part of a system of open spaces. Possible installations could range from vegetable and flower patches, meadows and grasslands, playgrounds and even small farms with animals. Most importantly the park fosters social interactions and a vibrant neighborhood. Active participation in creating and maintaining the landscape of any interested citizen are welcome. Furthermore the park can be utilized as a location for workshops and other events within the community, 
moreover as a semi-public space. For the municipality of Leipzig, this could be a cost-effective alternative to upgrade the entire area and deal with vacant spaces and this might not only be on a temporary basis.

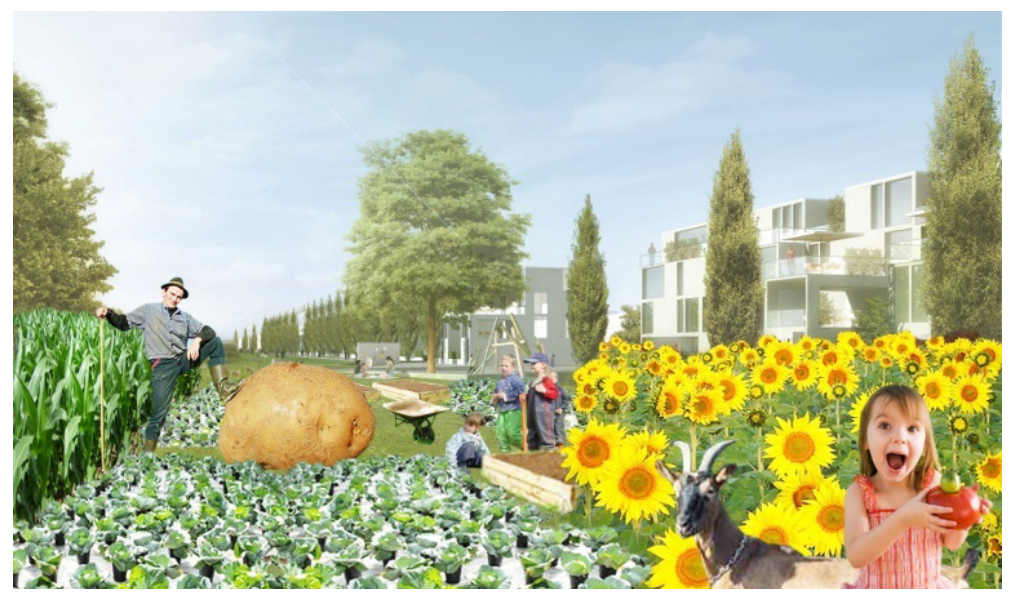

Figure 8: $\quad$ Leipzig Bayerischer Bahnhof $(\mathrm{N}+\mathrm{S})$.

\section{Conclusion}

In order to react on the demands of contemporary urban planning, a strategic set of rules should be generated which clearly defines fixed and flexible elements as well as basic structures but which also allows for openness. Within this apparent randomness, space - created by clearly defined open spaces - remains recognizable as a static linking system of order being a stable framework. Through the formulation of rules for the plots and a defined orientation of buildings, there is a basis for sustainable and successful urban planning.

Experiments on the search of new forms to create social and spatial diversity are the goal in order to activate locations and enable their acquisition. Counteracting the reduction of the city into gatherings of solitary architectural objects the coherence of single pieces within a stable framework must become a central endeavor. Non-harmonic, tensioned situations might be important initiators of innovative urban development projects. Wastelands and vacant buildings can be points of transition, unusual utilization concepts as well as explicit strategies for re-appropriation of space will enable generating a coherent network of subspaces while abolishing former partitions. Due to the fact that current transformation processes create a large number of those vacant spaces, it should be pursued to integrate the increasing number of vacant spaces as a vibrant part of the dynamic environment - and this way, it is possible to let the generic city become the specific city. 


\section{References}

[1] Lefebvre, H. (1974): Die Produktion des Raums. In: Dünne, J., Günzel, S. (Eds.). Raumtheorie. Grundlagentexte aus Philosophie und Kulturwissenschaften. Suhrkamp Taschenbuch Verlag. pp. 330-342. Frankfurt am Main, 2006.

[2] Koolhaas, R.: Die Stadt ohne Eigenschaften. In: Arch+ 132, Arch+ Verlag. pp. 18-27, Aachen, 1996.

[3] Eco, U.: Einführung in die Semiotik. Munich, 1972.

[4] Koolhaas, R. (1978): Delirious New York. Ein retroaktives Manifest für Manhattan, Arch+ Verlag. Aachen, 1999.

[5] DAM: New Urbanity - Die europäische Stadt des 21. Jahrhunderts, p.104 et seq. Verlag Anton Pustet. Vienna, 2008.

[6] Burdett, R.: 10th Int. Architecture Exhibition. Cities. Architecture and Society. Rizzoli International. New York, 2006.

[7] Christiaanse et al.: Aufgabe als Aufgabe. Entwurf und Strategie im perforierten Raum. In: Giseke/Spiegel (eds.): Stadtlichtungen. Irritationen, Perspektiven, Strategien. Berlin, 2007.

[8] Lohrberg, F: Urbane Agrarlandschaften, in: Valentin (Ed.): Return of Landscape. Berlin, 2010.

[9] Meiss, P. von (1986): Vom Objekt zum Raum zum Ort. Dimensionen der Architektur. Basel, 1994.

[10] Müller, C.: Urban Gardening - Über die Rückkehr der Gärten in die Stadt, oekom: München, 2011.

[11] Peterek, M.: Nachwort: Städtebau ist mehr als nur „vergrößerte“ Architektur - Zehn Thesen zur Beziehung zweier verwandter Disziplinen. In: Karlsruher Städtebauliche Schriften. Bd. 5 (1). Universitätsverlag. p. 99 et seq. Karlsruhe, 1994.

[12] Schmidt, D. and Stimpel, R.: Beet statt Baufeld, in: Deutsches Architektenblatt, Ausgabe Nordrhein-Westfalen 05/11, Düsseldorf.

[13] Sieverts, T.: Zwischenstadt zwischen Ort und Welt, Raum und Zeit, Stadt und Land, Bauwelt Fundamente 118. Vieweg. Braunschweig/Wiesbaden, 1997.

[14] Wolfrum, S.: Performativer Urbanismus. In: Broszat, T. et al. (ed.), Woodstock of Political Thinking. Munich, 2010. 